\title{
Ensino fundamental de nove anos: uma análise do processo de transição na região sul
}

\author{
Zenilde Durli ${ }^{1}$ \\ zenildedurli63@gmail.com \\ Marilda Pasqual Schneider ${ }^{2}$ \\ marilda.schneider@unoesc.edu.br
}

\section{Resumo}

Neste estudo, tem-se por objetivo discutir aspectos relacionados ao acesso e à permanência dos estudantes no Ensino Fundamental. Toma como ponto de partida um inventário de matrículas, levantado a partir do processo de transição do Ensino Fundamental de oito para o de nove anos nos estados que compõem a Região Sul do Brasil, e as taxas de aprovação, reprovação e abandono observadas no período. Põem em evidência os efeitos produzidos nas matrículas com a ampliação da escolaridade obrigatória e a crescente retração no Ensino Fundamental, fenômeno esse observado também em nível nacional. Chama-se a atenção para o necessário enfrentamento nas condições de permanência, com qualidade, no Ensino Fundamental.

Palavras-Chave: ensino fundamental de nove anos, acesso, permanência, qualidade

1 Doutora em Educação pela Universidade Federal de Santa Catarina. Professora da Universidade Federal de Santa Catarina.

2 Doutora em Educação pela Universidade Federal de Santa Catarina. Professora da Universidade do Oeste de Santa Catarina - Unoesc. 


\title{
Basic education of nine years: access to stay with quality
}

\begin{abstract}
The study aims to discuss aspects related to the access and permanence of students in elementary school. It takes as its starting point an inventory of license plates, raised from the transition process of elementary school of eight to nine years in the States that comprise the southern region of Brazil, and the rates of approval, disapproval and neglect observed in the period. Highlights the effects produced on license plates with the extension of compulsory schooling and the growing decline in elementary school, this phenomenon observed also at the national level. Draws attention to the need to confront in conditions of permanence, with quality, in elementary school.
\end{abstract}

Keywords: elementary school for nine years, access, permanence, quality

\section{Introdução}

As reformas no setor educacional, iniciadas no Brasil nas últimas décadas, vêm sendo arquitetadas sob os auspícios do movimento de reestruturação do Estado. A partir delas, a intervenção do Estado na condução das políticas educativas ascende a novo status, qual seja: o de regular a eficiência e eficácia dos sistemas de ensino públicos, fazendo emergir novos modos de regulação e de controle da qualidade educacional. Uma das políticas recentemente implantadas com essa finalidade é a ampliação da escolarização obrigatória, com a implantação do Ensino Fundamental de 9 Anos (EF9A).

Segundo os órgãos oficiais brasileiros (MEC, CNE, SEB), o EF9A emergiu como resposta à necessidade de melhoria desse nível de escolaridade, considerando a posição indesejável do Brasil na classificação organizada pelo Programa Internacional de Avaliação 
Escolar (PISA) ${ }^{1}$. Não obstante, sabe-se que essa não foi a única razão que motivou a ampliação da escolarização básica. Com essa decisão, o Brasil colocou em dia um dos compromissos assumidos por uma agenda regionalmente colocada no âmbito dos países da América Latina e do Caribe, segundo a qual esses países teriam se comprometido a oferecer uma educação geral, mínima, de oito a dez anos, antes de 1999. O Brasil chegou ao século XXI sem ter cumprido a meta estabelecida.

Além disso, com a implantação do Fundo de Manutenção e Desenvolvimento do Ensino Fundamental e de Valorização do Magistério (Fundef), em 1996, o financiamento do Ensino Fundamental para estados e municípios passou a ser em razão do número de alunos matriculados. Quanto maior o número de alunos, mais recursos são assegurados às redes públicas. Sem dúvida, essa medida e o compromisso assumido no âmbito da região latino-americana estimularam a inclusão das crianças com seis anos nas séries iniciais, em classes de alfabetização.

Considerando haver demanda para o atendimento dessa faixa etária no Ensino Fundamental, e que esta poderia ser contabilizada nas estatísticas oficiais melhorando os índices de cobertura de alunos na educação obrigatória, a ampliação do Ensino Fundamental para nove anos parecia não ser, ao menos do ponto de vista legal, um empreendimento difícil nas políticas educacionais em curso.

Assim, a Lei n. 11.114, promulgada em 16 de maio de 2005, ampliou a escolaridade obrigatória para nove anos, e a Lei n. 11.274, de 06 de fevereiro de 2006, tornou obrigatória a matrícula no Ensino Fundamental a partir dos seis anos de idade, estabelecendo o ano de 2010 como prazo para que municípios, estados e o Distrito Federal implementassem a determinação legal. A partir de 2010, todas as redes e os sistemas de ensino brasileiros deveriam estar com o EF9A devidamente

1 O PISA (Programme for International Student Assessment) é um programa internacional que avalia, a cada três anos, o desempenho educacional, de estudantes de 15 anos, em cada uma dessas áreas: leitura, Matemática e Ciência. Participam do Programa 65 países, incluindo o Brasil. Segundo dados do Inep, na avaliação do PISA de 2006, ano de publicação da Lei n. 11.274, que tornou obrigatória a oferta de nove anos de escolaridade para o Ensino Fundamental, o Brasil ocupava o $49^{\circ}$ lugar em leitura; $54^{\circ}$ lugar em Matemática; e $52^{\circ}$ lugar em Ciências. Essas posições renderam-lhe os últimos lugares na classificação dos países que participaram dos exames nos triênios até então avaliados. Informações disponíveis em: <http:// portal.inep.gov.br/pisa-programa-internacional-de-avaliacao-de-alunos>. Acesso em: 12 jan. 2013. 
regulamentado e em funcionamento nas escolas.

Ainda que indique um percurso natural em decorrência do processo histórico de ampliação gradativa do ensino obrigatório, a determinação de aumentar o alcance da escolaridade mínima não foi absorvida sem polêmica ou contestação. Tendo em conta a complexidade da educação básica brasileira, especialmente pela multiplicidade de sistemas de ensino que a compõe, essa política desaguou em diferentes interpretações que marcaram o processo de implantação e sua respectiva implementação nas redes de ensino e escolas. A falta de orientação e de esclarecimentos sobre as implicações e as intencionalidades dessa decisão constituiu um dos pontos sobre os quais ocorreram os principais embates erigidos e as controvérsias surgidas.

Estudos realizados no período ${ }^{2}$ evidenciam problemas e dificuldades enfrentados pelas escolas e redes de ensino na definição dos currículos, na gestão escolar, no processo de avaliação, entre outros, todos decorrentes da forma intempestiva com que a obrigatoriedade da ampliação do Ensino Fundamental chegou às escolas.

Decorridos dois anos da finalização do prazo para regulamentação das duas Leis (11.114/2005 e 11.274/2006) não é incomum encontrar instituições inseguras quanto ao rumo a seguir, especialmente em relação à proposta pedagógica e curricular das escolas, demarcando um conjunto de implicações irreversível no processo de implementação dessa política, nomeadamente para o grupo de alunos que participaram, à época, do processo de transição do ensino de oito para o de nove anos. Essas implicações produzem efeitos às condições de melhoria da qualidade educacional, bandeira edificada na política de implantação do EF9A.

Com base no exposto, o estudo em tela tem por objetivo discutir aspectos relacionados ao acesso e à permanência dos estudantes do Ensino Fundamental com a implantação do EF9A. Toma como ponto de partida um inventário de matrículas, levantado a partir do processo de transição do Ensino Fundamental de oito para o de nove anos nos estados que compõem a Região Sul do Brasil, e dados de aprovação, 
reprovação e abandono no período compreendido entre 2007 a 2010, com intuito de ilustrar os desafios da permanência com qualidade no Ensino Fundamental. Nesse inventário, põem em evidência os efeitos produzidos nas matrículas das redes com a implantação do EF9A e os compara com dados nacionais.

O estudo é parte de uma pesquisa maior, que tem por objetivo verificar como os sistemas estaduais de educação dos estados do Paraná, Santa Catarina e Rio Grande do Sul protagonizaram a proposta de reforma curricular, evidenciando o modus operandi da política de regulação operada pelo Governo Federal no contexto da implantação do Ensino Fundamental de 9 Anos.

Os dados coletados nesse estudo tomam como referência majoritária o ano da homologação da Lei n. 11.114/2005 e encerram em 2010, prazo estipulado pela Lei n. 11.274/2006 como limite máximo para a implantação do EF9A. A análise corrobora a identificação do movimento de implantação da obrigatoriedade de nove anos para o Ensino Fundamental, possibilitando a recolha de subsídios para a compreensão do fluxo escolar no processo de implantação dessas duas leis e do desafio da permanência com qualidade.

\section{Impactos nas matrículas no decurso do EF8A para o EF9A}

Historicamente, no Brasil, estabeleceu-se uma correlação entre qualidade e oportunidade de acesso aos serviços educacionais, especialmente na Educação Básica. Malgrado o problema da falta de acesso à Educação Infantil e ao Ensino Médio, o processo de expansão das oportunidades de escolarização, desencadeado especialmente a partir da década de 1940, oportunizou que chegássemos ao século XXI com um número de escolas suficiente para quase a totalidade de crianças do Ensino Fundamental ${ }^{3}$.

É verdade que em algumas regiões e estados brasileiros a questão da universalização do acesso ainda não está resolvida. “Há estados com

3 De acordo com dados do Censo Escolar de 2010, o Brasil possui 194.939 estabelecimentos de ensino básico para um total de 51,5 milhões de estudantes que frequentam essa etapa de escolarização. 
quatro turnos - o matutino, o intermediário, o vespertino e o noturno [...]" (FERNANDES, 2010, p. 192). Faltam creches para atender à demanda de Educação Infantil e atingir a meta de matrícula na pré-escola, posicionada em nosso ordenamento constitucional-legal como direito imediato das crianças. Não obstante, nos centros urbanos de ocupação mais antiga, o acesso à etapa obrigatória de escolarização está praticamente resolvido ${ }^{4}$ (OLIVEIRA; ARAÚJO, 2005).

Colocados na ordem do dia, o problema da universalização ao Ensino Fundamental, o tempo, a permanência e o avanço das crianças e jovens na escola representam fatores preponderantes nas atuais políticas erigidas para essa etapa de escolarização, consideradas as metas para a melhoria da qualidade da escola pública em vigor pelas políticas de avaliação educacional implantadas nas últimas décadas. A ampliação da obrigatoriedade do Ensino Fundamental para nove anos de duração, para a faixa etária dos 6 aos 14 anos de idade, regulamentada pelas Leis n. 11.114/05 e n. 11.274/06, respectivamente, promete avançar nessa direção, sinalizando um passo adiante na atenção aos fatores implicados nas condições de acesso à escolarização obrigatória.

Apesar do descompasso entre as duas leis que regulamentaram o processo de implantação do EF9A, visto que a primeira, promulgada em 16 de maio de 2005, estabeleceu a matrícula e a frequência à escola para crianças a partir dos seis anos e, somente a segunda, exarada em 06 de fevereiro de 2006, estabeleceu a ampliação da obrigatoriedade do Ensino Fundamental para nove anos de duração (FARENZENA, 2010), tem-se que, por meio delas, houve apenas a regulamentação de uma situação anunciada há alguns anos no cenário educacional brasileiro.

Segundo dados do Inep (BRASIL, 2004b), no ano de 2003, um contingente de 11.510 escolas públicas brasileiras ofertavam o Ensino Fundamental de 9 anos. Somente os estados do Acre, Mato Grosso do Sul, Rio Grande do Norte, Rondônia, Roraima e Sergipe não apresentavam nenhum tipo de ampliação do Ensino Fundamental até o ano de 2003 (BRASIL, 2004). Assim, na prática, e do ponto de vista da legalidade,

4 Segundo o IBGE, em 2008 a taxa de atendimento de crianças na faixa etária de 7 a 14 anos era de $98 \%$ (IBGE, 2009). 
o peso e impacto dessa política nas matrículas do Ensino Fundamental foram menores do que o esperado.

Posto que a partir do ano $2000^{5}$ as matrículas no Ensino Fundamental regular começaram a sofrer um processo de retração, estaria nessa decisão uma das explicações acerca dos motivos que levaram muitos estados brasileiros a adotar, prematuramente, a política de antecipação da entrada das crianças no Ensino Fundamental. Iniciado esse processo de retração no ano de 2000, chegamos a 2005 com 33.534.561 alunos matriculados no Ensino Fundamental regular, conforme demonstra a TAB. 1.

\section{TABELA 1}

Número de matrículas no Ensino Fundamental no Brasil, no período de 2005 a 2010, por rede de ensino

\begin{tabular}{c|c|c|c|c|c}
\hline Período & Total & Federal & Estadual & Municipal & Privada \\
\hline 2005 & 33.534 .561 & 25.728 & 12.145 .494 & 17.986 .570 & 3.376 .769 \\
2006 & 33.282 .663 & 25.031 & 11.825 .112 & 17.964 .543 & 3.467 .977 \\
2007 & 32.122 .273 & 24.276 & 11.332 .963 & 17.571 .366 & 3.193 .668 \\
2008 & 32.086 .700 & 25.622 & 11.000 .916 & 17.442 .158 & 3.618 .004 \\
2009 & 31.705 .528 & 25.005 & 10.572 .496 & 17.329 .638 & 3.778 .389 \\
2010 & 31.005 .341 & 25.425 & 10.116 .856 & 16.921 .822 & 3.941 .238 \\
Variação & & & & & \\
2005/2010\% & $\mathbf{- 7 , 5 4 \%}$ & $\mathbf{- 1 , 1 8 \%}$ & $\mathbf{- 1 6 , 7 0 \%}$ & $\mathbf{- 5 , 9 2 \%}$ & $\mathbf{1 6 , 7 2 \%}$ \\
\hline
\end{tabular}

Fonte: Inep (BRASIL, 2005b, 2006b, 2007, 2008, 2009b, 2010b).

A contar de 2005, constata-se que o número de matrículas no Ensino Fundamental vem diminuindo ano após ano nas escolas brasileiras. Observa-se maior retração entre os anos de 2006 e 2007. Em 2010, o contingente de 31.005.341 matrículas apresentou uma variação negativa de $-2,2 \%$ em relação a 2009, ou seja, menos 700.187 matrículas na passagem de um para outro ano.

No período compreendido entre os anos de 2005 e 2010, a variação negativa das matrículas foi de $-7,54 \%$. Esse percentual corresponde a

5 Dados do Inep (BRASIL, 2000, 2001) evidenciam que, em 1999, o Brasil contava com 36.059.742 alunos matriculados no Ensino Fundamental regular. No ano 2000, esse número caiu par 35.717.948, uma retração de 341.794 matrículas, chegando, em 2003, a um total de 34.438,749 alunos matriculados no Ensino Fundamental regular. 
uma diminuição de 28.476.121 alunos nessa etapa de ensino ao longo do período. Enquanto a rede estadual amarga a maior perda $(-16,70 \%)$, a rede privada de ensino, apesar de possuir a menor concentração de matrículas de todas as esferas em apreciação, é a única com variação positiva no período.

Ainda que se verifique retração no quadro geral de matrículas, adjudicada pelo Inep à contínua queda na taxa de natalidade, à diminuição nos índices de repetência e à constante correção da distorção idade-série, chama atenção o incremento que a rede privada vem demonstrando ao longo no período. De 2005 para 2006, logrou um acréscimo de 2,7\% nas matrículas do Ensino Fundamental. Em 2007, sofreu uma retração de $-7,91 \%$, mas se recuperou nos anos subsequentes, chegando a $2010 \mathrm{com}$ um aumento contínuo de $16,72 \%$. Considerando o quadro de retração das demais redes e o debate em torno da qualidade do ensino público, esse fato é, no mínimo, curioso.

A despeito da crescente retração, as redes municipais e estaduais concentram o maior número de matrículas no período. Em 2010, mais da metade das matrículas do Ensino Fundamental (54,57\%) estavam concentradas na rede municipal, conforme evidenciam os dados do Gráfico 1 .

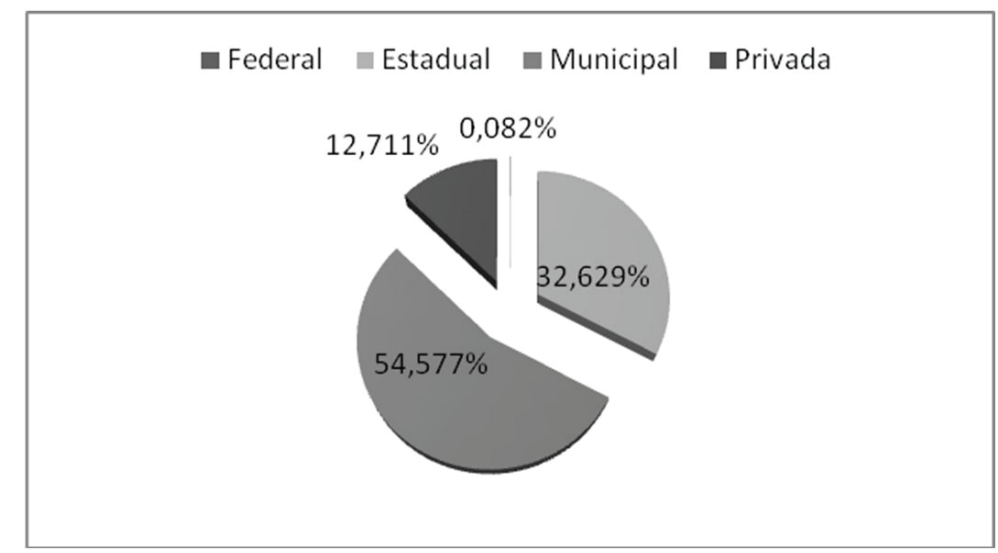

GRÁFICO 1 - Distribuição das matrículas do Ensino Fundamental, por redes de ensino no Brasil, no ano de 2010.

Fonte: Inep (BRASIL, 2005b, 2006b, 2007, 2008, 2009b, 2010b). 
A maior tutela para os municípios nessa etapa da educação básica encontra justificativa no processo de municipalização, desencadeado de forma sistemática no país a partir da LDB de 1996. À conta desse processo, olhando comparativamente para as redes, observa-se redução mais acentuada de matrícula no Ensino Fundamental na rede estadual, alcançando um decréscimo de 2.028.638 matrículas no período.

Considerando a responsabilidade dos municípios em prover a universalização da Educação Infantil, com a aprovação da Emenda Constitucional n. 59, de 11 de novembro de 2009 (EC n. 59/2009), que amplia a obrigatoriedade do ensino para a população de quatro a dezessete anos e estabelece como prazo para a sua implementação o ano de 2016, o planejamento da rede municipal, no que se refere à demanda de matrícula por série, é ainda mais proeminente. Mas não só. Municípios e estados deverão ser capazes de projetar o fluxo de matrículas ao longo das 14 séries (da pré-escola ao ensino médio), "até que se conclua a universalização, considerando tanto a taxa de inclusão da população que está fora do sistema, como a progressão dos alunos no sistema, ou seja, as taxas de conclusão, repetência e evasão." (PINTO; ALVES, 2010, p. 217). E esse, ao que tudo indica, constitui um dos maiores desafios.

Se considerarmos apenas a ampliação do Ensino Fundamental (para nove anos), o declínio no percentual de matrículas, no período compreendido entre 2005 a 2010, demonstra que houve maior absorção de crianças nessa etapa da educação básica, tornando sua demanda praticamente universalizada. Esse é um fato importante. No entanto, a exclusão de muitos, quer seja pelas possibilidades de acesso à Educação Básica (Educação Infantil e Ensino Médio), ou pelas condições de permanência e sucesso nas aprendizagens, ainda são fatores geradores de desigualdade e, portanto, de falta de qualidade na educação brasileira.

Observados os dados de aprovação, reprovação e abandono dos estudantes do Ensino Fundamental no período de 2007 a 2010, ou seja, desde o início do processo de regulamentação do EF9A, constatamos, ao longo do período, aumento nas taxas de aprovação e diminuição nas de reprovação e abandono, conforme demonstra o Gráfico 2. 


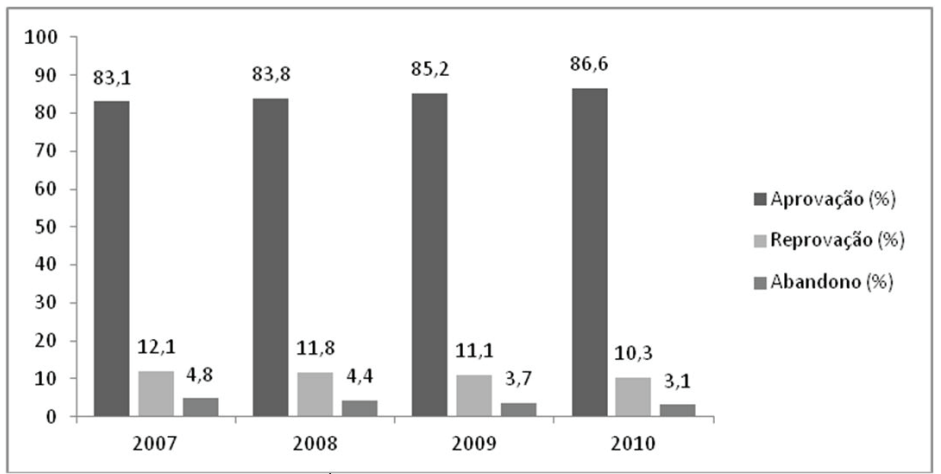

GRÁFICO 2 - Percentual de aprovação, reprovação e abandono no Ensino Fundamental (2007-2010)

Fonte: IBGE (2010, 2011).

Esse resultado, apesar de sinalizar que estamos no caminho certo no combate à evasão e à repetência, evidencia a persistência de um quadro desfavorável no que tange às perspectivas de sucesso escolar. Quadro esse marcado, especialmente, por um movimento lento de redução das condições de permanência no Ensino Fundamental.

É verdade que, se compararmos as taxas de abandono em período anterior à implantação da Lei n. 11.154/2005, verificaremos que o quadro atual é bem mais favorável. Em 1999, a taxa de abandono do Ensino Fundamental chegava a 11,3\%. Esse percentual caiu para 7,5\% em 2005 e atingiu o percentual de 3,1 em 2010 (IBGE, 2011). Não obstante, o percentual alcançado em 2010 sinaliza que mais de 3 milhões de crianças estão deixando as escolas brasileiras sem completar o Ensino Fundamental.

O que é ainda pior: apenas 47,6\% das crianças matriculadas no Ensino Fundamental concluem essa etapa de ensino até os quinze anos de idade (BRASIL, 2010b), tendo em conta a faixa etária de seis aos quatorze anos. Considerando que as taxas de aprovação compõem um dos dois indicadores do Índice de Desenvolvimento da Educação Básica (Ideb) ${ }^{6}$, criado em 2007 pelo Governo Federal, temos que a aferição da qualidade

6 O segundo indicador do Ideb é composto pelas notas obtidas na Prova Brasil, pelos estudantes de $4^{\mathrm{a}} / 5^{\mathrm{a}}$ Série e $8^{\mathrm{a}} / 9^{\mathrm{a}}$ série do Ensino Fundamental, e pelos da $3^{\mathrm{a}}$ série do Ensino Médio. 
na educação básica, passa, necessariamente, pelas condições de o aluno prosseguir seus estudos com êxito e sem interrupções.

Uma forma de se verificar o descompasso entre acesso e permanência é por meio da correlação entre o número de matrículas do Ensino Fundamental e do Ensino Médio. Em 2010, tínhamos 31.005.341 alunos matriculados no Ensino Fundamental versus 7.959.478 no Ensino Médio (BRASIL, 2010c). Esse número corresponde a um percentual de quase $75 \%$ de matrículas a menos no Ensino Médio que a observada no Ensino Fundamental.

Em 2010, havia 3.091.046 alunos matriculados na $8^{\mathrm{a}} / 9^{\circ}$ ano do Ensino Fundamental e 3.317.623 na $1^{\text {a }}$ série do Ensino Médio. O total de matrículas do Ensino Médio era de 7.959.478 alunos, considerando apenas o ensino regular (BRASIL, 2010a). Significa, via de regra, que o aluno concluinte do Ensino Fundamental tem pretensões de continuar seus estudos e, por isso, ingressa no Ensino Médio (alguns, é bem verdade, ingressam no Ensino Médio anos depois de concluir o Ensino Fundamental). No entanto, mais de 10\% deles irão abandonar os estudos antes de concluir o Ensino Médio. Outra parcela significativa (12\% deles) ficará retida em vista de reprovações (BRASIL, 2010a). Donde se conclui que o descompasso não se dá, exclusivamente, na passagem do Ensino Fundamental para o Médio, mas nas condições de avanço ao longo da Educação Básica.

Tendo em conta nosso interesse de observar o fenômeno do acesso e permanência em uma situação específica, observemos o mesmo quadro em relação aos estados que compõem a Região Sul do Brasil

\subsection{Situação das matrículas na Região Sul - Ensino Fundamental}

A Região Sul, formada pelos estados do Paraná, Santa Catarina e Rio Grande do Sul, é a menor do Brasil e a mais alfabetizada, com um percentual de $94,8 \%$ de alfabetizados dentre a população com dez anos ou mais de idade (BRASIL, 2010b). Em relação ao processo de implantação do EF9A, ratifica-se na Região situação verificada no período de 2005 e 2010 em âmbito nacional.

A análise da situação das matrículas nesses estados corrobora 
a tendência de retração geral no quadro de matrículas do Ensino Fundamental, com maior concentração na rede municipal de ensino e considerável aumento na rede privada.

Dentre os três estados que integram a Região, o Paraná detém o maior número de alunos matriculados no Ensino Fundamental, com 5,3\% do total de matrículas do país nessa etapa de escolarização. No período compreendido entre os anos de 2005 a 2010, esse estado teve uma queda de 13.863 matrículas, conforme pode ser observado na TAB. 2.

\section{TABELA 2}

Número de matrículas no Ensino Fundamental no estado do Paraná, no período de 2005 a 2010, por rede de ensino

\begin{tabular}{c|c|c|c|c|c}
\hline Período & Total & Federal & Estadual & Municipal & Privada \\
\hline 2005 & 1.653 .529 & 476 & 741.430 & 773.843 & 137.780 \\
2006 & 1.659 .903 & - & 760.016 & 761.278 & 138.609 \\
2007 & 1.677 .803 & 477 & 752.679 & 784.131 & 140.516 \\
2008 & 1.690 .852 & 491 & 752.717 & 783.692 & 153.952 \\
2009 & 1.677 .128 & 521 & 744.913 & 769.073 & 162.621 \\
2010 & 1.639 .666 & 494 & 725.147 & 746.268 & 167.757 \\
Variação & & & & & \\
$2005 / 2010 \%$ & $\mathbf{- 0 , 8 4 \%}$ & $\mathbf{3 , 7 8} \%$ & $\mathbf{- 2 , 2 0 \%}$ & $\mathbf{- 3 , 5 6 \%}$ & $\mathbf{2 1 , 7 6 \%}$ \\
\hline
\end{tabular}

Fonte: Inep (BRASIL, 2005b, 2006b, 2007, 2008, 2009b, 2010b).

Chama atenção um aumento de 13.049 matrículas no ano de 2008, evidenciando, justamente, o ano no qual o processo de implantação foi mais expressivo em todas as redes de ensino daquele estado, com a inclusão das crianças de seis anos no Ensino Fundamental. O crescimento das matrículas na rede particular é ainda mais expressivo que em âmbito nacional, alcançando, no período de seis anos, um crescimento de $21,76 \%$.

Santa Catarina, por sua vez, concentra cerca de $2 \%$ do total das matrículas do país no ano de 2010, apresentando o menor número de alunos no Ensino Fundamental entre os três estados sulinos. No período amostrado, o estado logrou redução de 62.370 matrículas, o que representa um índice negativo de $-6,62 \%$, mais acentuado nos anos de 2009 e 2010, conforme demonstrado na TAB. 3. 
TABELA 3

Número de matrículas no Ensino Fundamental, no estado de Santa Catarina, no período de 2005 a 2010, por rede de ensino.

\begin{tabular}{c|c|c|c|c|c}
\hline Período & Total & Federal & Estadual & Municipal & Privada \\
\hline 2005 & 942.382 & 614 & 438.869 & 428.331 & 74.568 \\
2006 & 951.192 & 599 & 437.682 & 438.543 & 74.368 \\
2007 & 920.337 & 612 & 414.178 & 436.424 & 69.123 \\
2008 & 914.582 & 644 & 406.748 & 430.324 & 76.866 \\
2009 & 897.791 & 651 & 395.212 & 421.916 & 80.012 \\
2010 & 880.012 & 656 & 384.125 & 412.614 & 82.617 \\
Variação & & & & & \\
2005/2010\% & $\mathbf{- 6 , 6 2 \%}$ & $\mathbf{6 , 8 4 \%}$ & $\mathbf{- 1 2 , 4 7 \%}$ & $\mathbf{- 3 , 6 7 \%}$ & $\mathbf{1 0 , 7 9 \%}$ \\
\hline
\end{tabular}

Fonte: Inep (BRASIL, 2005b, 2006b, 2007, 2008, 2009b, 2010b).

Em relação à distribuição das matrículas nas redes de ensino de Santa Catarina, observa-se redução significativa na estadual, configurando diferença de 54.744 estudantes no período amostrado e concentração mais significativa entre os anos de 2006 e 2007. A rede municipal registrou pequeno aumento nas matrículas no ano de 2006, mas que não compensou a redução identificada nas demais redes. Em 2005, o maior percentual de matrículas ficou concentrado na rede estadual, quadro que se altera nos anos subsequentes, consoante o que ocorre no cenário nacional.

O estado do Rio Grande do Sul concentrou, em 2010, cerca de 4,9\% das matrículas do Ensino Fundamental do país, com redução de 101.720 entradas de alunos no período. A partir de 2007, a redução nas matrículas é um fator constante também nesse estado, acumulando um índice de menos $6,24 \%$ no período, conforme TAB. 4 . 


\section{TABELA 4}

Número de matrículas no Ensino Fundamental, no estado do Rio Grande do Sul, no período de 2005 a 2010, por rede de ensino.

\begin{tabular}{c|c|c|c|c|c}
\hline Período & Total & Federal & Estadual & Municipal & Privada \\
\hline 2005 & 1.631 .270 & 1.334 & 771.303 & 726.015 & 132.618 \\
2006 & 1.645 .652 & 1.307 & 748.501 & 761.960 & 133.884 \\
2007 & 1.627 .867 & 1.319 & 744.522 & 751.364 & 130.662 \\
2008 & 1.598 .403 & 1.290 & 721.811 & 740.749 & 134.553 \\
2009 & 1.565 .961 & 1.310 & 694.416 & 733.970 & 136.265 \\
2010 & 1.529 .550 & 1.372 & 667.770 & 721.608 & 138.800 \\
Variação & & & & & \\
$2005 / 2010 \%$ & $\mathbf{- 6 , 2 4 \%}$ & $\mathbf{2 , 8 5 \%}$ & $\mathbf{- 1 3 , 4 2 \%}$ & $\mathbf{- 0 , 6 1 \%}$ & $\mathbf{4 , 6 6 \%}$ \\
& & & & & \\
\hline
\end{tabular}

Fonte: Inep (BRASIL, 2005b, 2006b, 2007, 2008, 2009b, 2010b).

Quanto à distribuição das matrículas nas redes de ensino, no Rio Grande do Sul, ocorre situação análoga aos demais estados amostrados, com maior concentração na rede municipal. Essa é responsável por $47,18 \%$ das matrículas no ano de 2010, enquanto a rede estadual responde por $43,66 \%$ do total do estado.

Mesmo com a ampliação da escolaridade obrigatória e a inserção das crianças com seis anos de idade no Ensino Fundamental, não houve incremento no número de matrículas nos três estados sulinos. Pelo contrário, observou-se um movimento de redução constante no período. Essa constatação corrobora a hipótese de que as decisões de um governo não têm o poder de determinar o social. Antes, interagem com ele, sendo, na maioria das vezes, por ele constrangida.

Porquanto a transição do Ensino Fundamental de oito para nove anos se deu de forma gradativa, ainda que a promulgação da lei tenha sido considerada abrupta por muitos gestores e professores, é importante verificar o impacto nas matrículas do Ensino Fundamental ao longo do período. Com o intuito de identificar esse movimento de transição, e o momento mais significativo da passagem das matrículas do EF8A para o EF9A, consultamos os dados disponíveis no Inep em relação ao cenário nacional e aos estados amostrados, conforme segue. 


\section{TABELA 5}

Número de matrículas no Ensino Fundamental de 8 anos no Brasil, no período de 2005 a 2010, por rede de ensino

\begin{tabular}{c|c|c|c|c|c|c}
\hline \multicolumn{2}{c}{} & \multicolumn{5}{c}{ EF8A } \\
\cline { 2 - 7 } \multicolumn{2}{c}{ Total EF8A e EF9A } & Total & Federal & Estadual & Municipal & Privada \\
\hline 2005 & 33.534 .561 & 25.420 .742 & 19.785 & 9.396 .053 & 12.759 .634 & 3.245 .270 \\
2006 & 33.282 .663 & 22.617 .048 & 15.968 & 8.715 .334 & 11.032 .510 & 2.853 .236 \\
2007 & 32.122 .273 & 17.902 .029 & 12.824 & 7.438 .755 & 8.916 .312 & 1.534 .138 \\
2008 & 32.086 .700 & 15.454 .671 & 4.429 & 6.762 .979 & 7.440 .618 & 1.246 .645 \\
2009 & 31.705 .528 & 12.994 .972 & 2.849 & 6.037 .154 & 5.968 .610 & 986.359 \\
2010 & 31.005 .341 & 10.488 .210 & 2.463 & 5.295 .845 & 4.453 .960 & 735.942 \\
Variação & & & & & & \\
$2005 / 2010 \%$ & $-\mathbf{7 , 5 4 \%}$ & $\mathbf{- 5 8 , 7 4 \%}$ & $\mathbf{- 8 7 , 5 5 \%}$ & $\mathbf{- 4 3 , 6 4 \%}$ & $\mathbf{- 6 5 , 0 9 \%}$ & $\mathbf{- 7 7 , 3 2 \%}$ \\
\hline
\end{tabular}

Fonte: Inep (BRASIL, 2005b, 2006b, 2007, 2008, 2009b, 2010b).

No início do processo de ampliação da escolaridade obrigatória posto em marcha em 2005, 75,80\% das matrículas do Ensino Fundamental estavam concentradas no regime de oito anos. Em 2010, o percentual de matrículas no EF8A caiu para 33,83\%; diferença mais significativa ocorreu entre os anos de 2006 e 2007. Em 2005, 24,20\% de matrículas já estavam alocadas no regime de nove anos e, em 2010, esse percentual alcançou $66,17 \%$.

Os dados relevam que, ao término do prazo legal definido para a transição do regime de oito para o de nove anos, grande parte das redes efetuou a ampliação determinada. O percentual significativo de matrículas que ainda estão alocadas no EF8A demonstra, no entanto, uma transição em processo. Considerando a modalidade de implantação gradativa e os anos de 2006 e 2007 como de início sistemático dessa passagem, a transição dos anos iniciais estaria consolidada entre 2011 e 2012. Só então os anos finais iniciariam a implantação. Essa constatação justifica o percentual de matrículas, ainda existentes, no EF8A, em 2010, conforme demonstra a TAB. 6. 


\section{TABELA 6}

Número de matrículas no Ensino Fundamental de 9 anos no Brasil, no período de 2005 a 2010, por rede de ensino.

\begin{tabular}{c|c|c|c|c|c|c}
\hline \multirow{2}{*}{\multicolumn{2}{c|}{ Total EF8A e EF9A }} & \multicolumn{5}{c}{ EF9A } \\
\cline { 2 - 7 } & Total & Federal & Estadual & Municipal & Privada \\
\hline 2005 & 33.534 .561 & 8.113 .819 & 5.943 & 2.749 .441 & 5.226 .936 & 131.499 \\
2006 & 33.282 .663 & 10.665 .615 & 9.063 & 3.109 .778 & 6.932 .033 & 614.741 \\
2007 & 32.122 .273 & 14.220 .244 & 11.452 & 3.894 .208 & 8.655 .054 & 1.659 .530 \\
2008 & 32.086 .700 & 16.632 .029 & 21.193 & 4.237 .937 & 10.001 .540 & 2.371 .359 \\
2009 & 31.705 .528 & 18.710 .556 & 22.156 & 4.535 .342 & 11.361 .028 & 2.792 .030 \\
2010 & 31.005 .341 & 20.517 .131 & 22.962 & 4.821 .011 & 12.467 .862 & 3.205 .296 \\
Variação & & & & & & \\
$2005 / 2010 \%$ & $-7,54 \%$ & $\mathbf{1 5 2 , 8 7 \%}$ & $\mathbf{2 8 6 , 3 7 \%}$ & $\mathbf{7 5 , 3 5 \%}$ & $\mathbf{1 3 8 , 5 3 \%}$ & $\mathbf{2 3 3 7 , 5 1 \%}$ \\
\hline
\end{tabular}

Fonte: Inep (BRASIL, 2005b, 2006b, 2007, 2008, 2009b, 2010b).

No total de matrículas do EF9A, constata-se transição mais intensa, em movimento análogo ao verificado nos números relativos ao EF8A, justamente nos anos de 2006 e 2007, conforme pode ser mais bem observado no Gráfico 2. A variação é significativamente mais expressiva nas redes federal e particular. Exatamente as duas que apresentaram aumento no número de matrículas no período em estudo. Além disso, sabe-se que, na rede particular, houve, em muitos casos, a implantação simultânea da ampliação, especialmente para os anos finais do Ensino Fundamental.

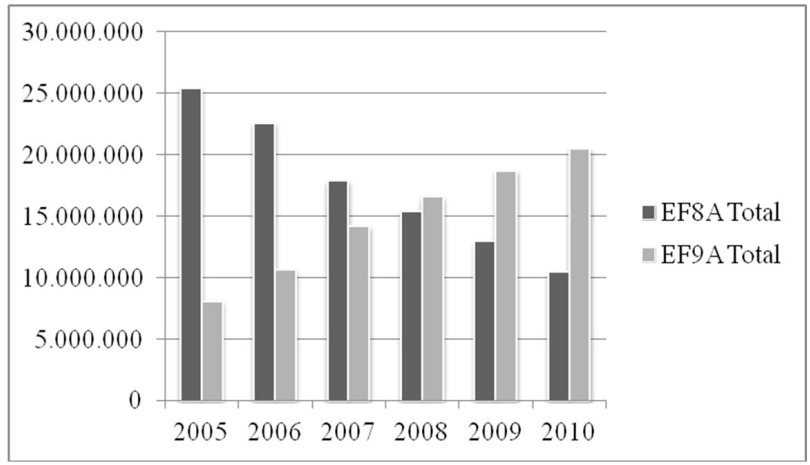

GRÁFICO 3 - Número de matrículas no Ensino Fundamental de 8 e 9 anos no Brasil, no período de 2005 a 2010 Fonte: Inep (BRASIL, 2005b, 2006b, 2007, 2008, 2009b, 2010b). 
Se, por um lado, temos o aumento gradativo das matrículas no EF9A, por outro, fica evidente a retração, também gradativa, no número de matrículas, que teve uma variação de $-7,54 \%$ ao longo do período. Esse fenômeno nacional é confirmado também nos três estados da Região Sul, ainda que o percentual de retração seja inferior ao da média nacional.

No estado do Paraná, no ano de 2010, 66,79\% do total de 1.639 .666 matrículas ainda estavam alocadas no EF8A e somente 33,21\% no EF9A, conforme pode ser observado nas TAB. 7 e 8, respectivamente.

\section{TABELA 7}

Número de matrículas no Ensino Fundamental de 8 anos no estado do Paraná, no período de 2005 a 2010, por rede de ensino

\begin{tabular}{c|c|c|c|c|c|c}
\hline \multicolumn{2}{c}{} & \multicolumn{5}{c}{ EF8A } \\
\cline { 2 - 7 } \multicolumn{2}{c}{ Total EF8A e EF9A } & Total & Federal & Estadual & Municipal & Privada \\
\hline 2005 & 1.653 .529 & 1.527 .154 & 476 & 741.430 & 647.468 & 137.780 \\
2006 & 1.659 .903 & 1.537 .532 & - & 760.016 & 638.977 & 138.539 \\
2007 & 1.677 .803 & 1.584 .781 & 477 & 752.679 & 701.536 & 130.089 \\
2008 & 1.690 .852 & 1.462 .906 & - & 752.395 & 584.783 & 125.728 \\
2009 & 1.677 .128 & 1.291 .090 & - & 744.264 & 433.360 & 113.466 \\
2010 & 1.639 .666 & 1.095 .123 & 0 & 724.120 & 274.212 & 96.791 \\
Variação & & & & & & \\
$2005 / 2010 \%$ & $-\mathbf{0 , 8 4 \%}$ & $\mathbf{- 2 8 , 2 9 \%}$ & $\mathbf{- 1 0 0 , 0 0 \%}$ & $\mathbf{- 2 , 3 3 \%}$ & $\mathbf{- 5 7 , 6 5 \%}$ & $\mathbf{- 2 9 , 7 5 \%}$ \\
\hline
\end{tabular}

Fonte: Inep (BRASIL, 2005b, 2006b, 2007, 2008, 2009b, 2010b). 


\section{TABELA 8}

Número de matrículas no Ensino Fundamental de 9 anos no estado do Paraná, no período de 2005 a 2010, por rede de ensino

\begin{tabular}{c|c|c|c|c|c|c}
\hline \multirow{2}{*}{\multicolumn{2}{c|}{ Total EF8A e EF9A }} & \multicolumn{5}{c}{ EF9A } \\
\cline { 2 - 7 } & Total & Federal & Estadual & Municipal & Privada \\
\hline 2005 & 1.653 .529 & 126.375 & - & - & 126.375 & - \\
2006 & 1.659 .903 & 122.371 & - & - & 122.301 & 70 \\
2007 & 1.677 .803 & 93.022 & - & - & 82.595 & 10.427 \\
2008 & 1.690 .852 & 227.946 & 491 & 322 & 198.909 & 28.224 \\
2009 & 1.677 .128 & 386.038 & 521 & 649 & 335.713 & 49.155 \\
2010 & 1.639 .666 & 544.543 & 494 & 1.027 & 472.056 & 70.966 \\
Variação & & & & & & \\
$2005 / 2010 \%$ & $\mathbf{- 0 , 8 4 \%}$ & $\mathbf{3 3 0 , 8 9 \%}$ & & & $\mathbf{2 7 3 , 5 4 \%}$ & \\
\hline
\end{tabular}

Fonte: Inep (BRASIL, 2005b, 2006b, 2007, 2008, 2009b, 2010b).

No Paraná, observa-se movimento mais intenso de transição, em todas as redes, na passagem de 2007 para 2008. A rede estadual apresenta pouca movimentação de matrículas de uma modalidade para outra, pois, tendo optado pela implantação gradativa iniciando pelas primeiras séries/ anos e considerando que, naquele estado, elas estão praticamente sob a responsabilidade da rede municipal, conclui-se que a transição será maior nas séries finais, possivelmente a partir de 2010.

Na rede municipal, a transição para nove anos é mais perceptível, pois das 544.543 matrículas efetuadas no EF9A, 86,69\% estão na rede municipal de ensino. A variação no índice de matriculados no EF9A alcança $273,54 \%$ no período. A rede Federal provavelmente procedeu à implantação simultânea, pois em 2008 houve migração completa do EF8A para o EF9A.

Em Santa Catarina, no ano de 2010, do total de 880.012 matrículas, $45,82 \%$ estão concentradas no EF8A e 54,18\% no EF9A, conforme demonstrado nas TAB. 9 e 10, respectivamente, configurando cenário distinto do apresentado pelo estado do Paraná. 


\section{TABELA 9}

Número de matrículas no Ensino Fundamental de 8 anos no estado de Santa Catarina, no período de 2005 a 2010, por rede de ensino

\begin{tabular}{c|c|c|c|c|c|c}
\hline \multirow{2}{*}{\multicolumn{2}{c|}{ Total EF8A e EF9A }} & \multicolumn{5}{c}{ EF8A } \\
\cline { 2 - 7 } & Total & Federal & Estadual & Municipal & Privada \\
\hline 2005 & 942.382 & 862.155 & 614 & 438.869 & 348.360 & 74.312 \\
2006 & 951.192 & 829.030 & 599 & 437.682 & 318.447 & 72.302 \\
2007 & 920.337 & 672.521 & 592 & 374.485 & 254.739 & 42.705 \\
2008 & 914.582 & 586.167 & 586 & 337.725 & 213.422 & 34.434 \\
2009 & 897.791 & 501.669 & - & 295.123 & 179.366 & 27.180 \\
2010 & 880.012 & 403.235 & 0 & 249.873 & 131.108 & 22.254 \\
Variação & & & & & & \\
$2005 / 2010 \%$ & $-6,62 \%$ & $-53,23 \%$ & $-\mathbf{1 0 0 , 0 0 \%}$ & $\mathbf{- 4 3 , 0 6 \%}$ & $\mathbf{- 6 2 , 3 6 \%}$ & $\mathbf{- 7 0 , 0 5 \%}$ \\
\hline
\end{tabular}

Fonte: Inep (BRASIL, 2005b, 2006b, 2007, 2008, 2009b, 2010b).

\section{TABELA 10}

Número de matrículas no Ensino Fundamental de 9 anos no estado de Santa Catarina, no período de 2005 a 2010, por rede de ensino

\begin{tabular}{c|c|c|c|c|c|c}
\hline \multirow{2}{*}{\multicolumn{2}{c|}{}} & \multicolumn{5}{c}{ EF9A } \\
\cline { 2 - 7 } \multicolumn{2}{c}{ Total EF8A e EF9A } & Total & Federal & Estadual & Municipal & Privada \\
\hline 2005 & 942.382 & 80.227 & - & - & 79.971 & 256 \\
2006 & 951.192 & 122.162 & - & - & 120.096 & 2.066 \\
2007 & 920.337 & 247.816 & 20 & 39.693 & 181.685 & 26.418 \\
2008 & 914.582 & 328.415 & 58 & 69.023 & 216.902 & 42.432 \\
2009 & 897.791 & 396.122 & 651 & 100.089 & 242.550 & 52.832 \\
2010 & 880.012 & 476.777 & 656 & 134.252 & 281.506 & 60.363 \\
Variação & & & - & - & & \\
$2005 / 2010 \%$ & $\mathbf{- 6 , 6 2 \%}$ & $\mathbf{4 9 4 , 2 8 \%}$ & & & $\mathbf{2 5 2 , 0 1 \%}$ & $\mathbf{2 3 4 7 9 , 3 0 \%}$ \\
\hline
\end{tabular}

Fonte: Inep (BRASIL, 2005b, 2006b, 2007, 2008, 2009b, 2010b).

A implantação do EF9A nas escolas estaduais catarinenses ocorreu em 2007. Por isso, percebe-se movimentação significativa a partir daquele ano, conforme demonstram os dados da TAB. 10. Nesse 
período, considerando a ampliação gradual, na rede estadual, as séries / anos iniciais estariam em transição para o novo regime, enquanto as séries finais deverão iniciar essa movimentação apenas no ano de 2012. Conforme apontam estudos de Schneider e Durli (2009a, 2009b), na maioria das redes públicas do sistema municipal, a transição ocorreu entre os anos de 2007 e 2008.

Chama atenção o percentual de retração do número total de matrículas desse estado ao longo do período (-6,62\%), bem superior ao do estado do Paraná e muito próximo do percentual de retração observado no contexto nacional (-7,54\%). Embora adversa ao estado do Paraná, a situação das matrículas em Santa Catarina é assemelhada ao de seu outro estado vizinho, o Rio Grande do Sul. No ano de 2010, do total de 1.529.550 matrículas no Ensino Fundamental, 51,68\% estavam concentradas no EF8A e 48,32\% no EF9A, conforme demonstram as TAB. 11 e 12 , respectivamente.

\section{TABELA 11}

Número de matrículas no Ensino Fundamental de 8 anos no estado do Rio Grande do Sul, no período de 2005 a 2010, por rede de ensino

\begin{tabular}{c|c|c|c|c|c|c}
\hline \multirow{2}{*}{\multicolumn{2}{c|}{ Total EF8A e EF9A }} & \multicolumn{5}{c}{ EF8A } \\
\cline { 2 - 7 } & Total & Federal & Estadual & Municipal & Privada \\
\hline 2005 & 1.631 .270 & 1.492 .537 & 1.334 & 764.524 & 594.472 & 132.207 \\
2006 & 1.645 .652 & 1.415 .147 & 1.307 & 741.672 & 540.675 & 131.493 \\
2007 & 1.627 .867 & 1.318 .937 & 1.319 & 706.696 & 488.689 & 122.233 \\
2008 & 1.598 .403 & 1.142 .534 & 292 & 609.526 & 423.148 & 109.568 \\
2009 & 1.565 .961 & 972.684 & 266 & 519.693 & 357.652 & 95.073 \\
2010 & 1.529 .550 & 790.439 & 237 & 432.766 & 277.737 & 79.699 \\
Variação & & & & & & \\
$2005 / 2010 \%$ & $\mathbf{- 6 , 2 4 \%}$ & $\mathbf{- 4 7 , 0 4 \%}$ & $\mathbf{- 8 2 , 2 3 \%}$ & $\mathbf{- 4 3 , 3 9 \%}$ & $\mathbf{- 5 3 , 2 8 \%}$ & $\mathbf{- 3 9 , 7 2 \%}$ \\
\hline
\end{tabular}

Fonte: Inep (BRASIL, 2005b, 2006b, 2007, 2008, 2009b, 2010b). 


\section{TABELA 12}

Número de matrículas no Ensino Fundamental de 9 anos no estado do Rio Grande do Sul, no período de 2005 a 2010, por rede de ensino

\begin{tabular}{c|c|c|c|c|c|c}
\hline \multirow{2}{*}{\multicolumn{2}{c|}{ Total EF8A e EF9A }} & \multicolumn{5}{c}{ EF9A } \\
\cline { 2 - 7 } & Total & Federal & Estadual & Municipal & Privada \\
\hline 2005 & 1.631 .270 & 138.733 & - & 6.779 & 131.543 & 411 \\
2006 & 1.645 .652 & 230.505 & - & 6.829 & 221.285 & 2.391 \\
2007 & 1.627 .867 & 308.930 & - & 37.826 & 262.675 & 8.429 \\
2008 & 1.598 .403 & 455.869 & 998 & 112.285 & 317.601 & 24.985 \\
2009 & 1.565 .961 & 593.277 & 1.044 & 174.723 & 376.318 & 41.192 \\
2010 & 1.529 .550 & 739.111 & 1.135 & 235.004 & 443.871 & 59.101 \\
Variação & & & & & & \\
$2005 / 2010 \%$ & $\mathbf{- 6 , 2 4 \%}$ & $\mathbf{4 3 2 , 7 6 \%}$ & & $\mathbf{3 3 6 6 , 6 5 \%}$ & $\mathbf{2 3 7 , 4 3 \%}$ & $\mathbf{1 4 2 7 9 , 8 1 \%}$ \\
\hline
\end{tabular}

Fonte: Inep (BRASIL, 2005b, 2006b, 2007, 2008, 2009b, 2010b).

No Rio Grande do Sul, houve uma movimentação regular no quadro de matrículas em todos os anos do período, considerando que, nas redes municipal e particular, o processo de transição se inicia no ano de 2006. Na rede estadual, a transição mais significativa do EF8A para o EF9A ocorre no ano de 2008, mantendo uma progressão regular nos anos seguintes, porém não sendo concluída até o final do período (2010), conforme demonstram os dados das TAB. 11 e 12. O mesmo ocorre na rede municipal.

\section{TABELA 13}

Percentual de matrículas no Ensino Fundamental de 8 e 9 anos no Brasil, PR, SC e RS, no período de 2005 a 2010

\begin{tabular}{c|c|c|c|c|c|c|c|c}
\hline \multirow{2}{*}{} & \multicolumn{2}{|c|}{ Total BR } & \multicolumn{2}{c|}{ Total PR } & \multicolumn{2}{c|}{ Total SC } & \multicolumn{2}{c}{ Total RS } \\
\cline { 2 - 8 } Período & EF8A & EF9A & EF8A & EF9A & EF8A & EF9A & EF8A & EF9A \\
2005 & $75,80 \%$ & $24,20 \%$ & $92,36 \%$ & $7,64 \%$ & $91,49 \%$ & $8,51 \%$ & $91,50 \%$ & $8,50 \%$ \\
2006 & $67,95 \%$ & $32,05 \%$ & $92,63 \%$ & $7,37 \%$ & $87,16 \%$ & $12,84 \%$ & $85,99 \%$ & $14,01 \%$ \\
2007 & $55,73 \%$ & $44,27 \%$ & $94,46 \%$ & $5,54 \%$ & $73,07 \%$ & $26,93 \%$ & $81,02 \%$ & $18,98 \%$ \\
2008 & $48,17 \%$ & $51,83 \%$ & $86,52 \%$ & $13,48 \%$ & $64,09 \%$ & $35,91 \%$ & $71,48 \%$ & $28,52 \%$ \\
2009 & $40,99 \%$ & $59,01 \%$ & $76,98 \%$ & $23,02 \%$ & $55,88 \%$ & $44,12 \%$ & $62,11 \%$ & $37,89 \%$ \\
2010 & $33,83 \%$ & $66,17 \%$ & $66,79 \%$ & $33,21 \%$ & $45,82 \%$ & $54,18 \%$ & $51,68 \%$ & $48,32 \%$ \\
\hline
\end{tabular}

Fonte: Inep (BRASIL, 2005b, 2006b, 2007, 2008, 2009b, 2010b). 
Analisando a movimentação das matrículas do EF8A para o EF9A no período e a situação no ano de 2010, verifica-se transição mais lenta nas redes de ensino do Paraná, com 33,21\% das matrículas no EF9A; em seguida vem o Rio Grande do Sul, com 48,32\%, e, destacando-se dos demais, está Santa Catarina, com 54,18\% das matrículas já alocadas no EF9A, conforme demonstrado nas TAB. 14 e 15.

\section{TABELA 14}

Total de matrículas no Ensino Fundamental de 8 e 9 anos no Brasil, PR, SC e RS em 2010

\begin{tabular}{c|c|c|c|c|c|c|c|c}
\hline \multirow{4}{*}{} & \multicolumn{2}{|c|}{ Total BR } & \multicolumn{2}{c|}{ Total PR } & \multicolumn{2}{c|}{ Total SC } & \multicolumn{2}{c}{ Total RS } \\
\cline { 2 - 9 } & EF8A & EF9A & EF8A & EF9A & EF8A & EF9A & EF8A & EF9A \\
Total & BR & BR & PR & PR & SC & SC & RS & RS \\
Federal & 20.488 .210 & 20.517 .131 & 1.095 .123 & 544.543 & 403.235 & 476.777 & 790.439 & 739.111 \\
Estadual & 5.295 .845 & 22.962 & 0 & 494 & 0 & 656 & 237 & 1.135 \\
Municipal & 4.453 .960 & 12.467 .862 & 274.212 & 472.056 & 131.108 & 281.506 & 277.737 & 443.871 \\
Privado & 735.942 & 3.205 .296 & 96.791 & 70.966 & 22.254 & 60.363 & 79.699 & 59.101 \\
\hline
\end{tabular}

Fonte: Inep (BRASIL, 2005b, 2006b, 2007, 2008, 2009b, 2010b).

\section{TABELA 15}

Percentual de matrículas no Ensino Fundamental de 8 e 9 anos no Brasil, PR, SC e RS em 2010

\begin{tabular}{c|c|c|c|c|c|c|c|c}
\hline \multirow{2}{*}{} & \multicolumn{2}{|c|}{ Total BR } & \multicolumn{2}{c|}{ Total PR } & \multicolumn{2}{c|}{ Total SC } & \multicolumn{2}{c}{ Total RS } \\
\cline { 2 - 8 } & EF8A & EF9A & EF8A & EF9A & EF8A & EF9A & EF8A & EF9A \\
& BR & BR & PR & PR & SC & SC & RS & RS \\
Total & $33,83 \%$ & $66,17 \%$ & $66,79 \%$ & $33,21 \%$ & $45,82 \%$ & $54,18 \%$ & $51,68 \%$ & $48,32 \%$ \\
Federal & $9,69 \%$ & $90,31 \%$ & $0,00 \%$ & ---- & $0,00 \%$ & ---- & $17,27 \%$ & $82,73 \%$ \\
Estadual & $52,35 \%$ & $47,65 \%$ & $99,86 \%$ & $0,14 \%$ & $65,05 \%$ & $34,95 \%$ & $64,81 \%$ & $35,19 \%$ \\
Municipal & $26,32 \%$ & $73,68 \%$ & $36,74 \%$ & $63,26 \%$ & $31,77 \%$ & $68,23 \%$ & $38,49 \%$ & $61,51 \%$ \\
Privado & $18,67 \%$ & $81,33 \%$ & $57,70 \%$ & $42,30 \%$ & $26,94 \%$ & $73,06 \%$ & $57,42 \%$ & $42,58 \%$ \\
\hline
\end{tabular}

Fonte: Inep (BRASIL, 2005b, 2006b, 2007, 2008, 2009b, 2010b).

No ano de 2010, do total das matrículas da Região Sul no Ensino Fundamental, 33,83\% delas estava concentrado no EF8A e $66,17 \%$ no EF9A. No cenário da transição para EF9A, o Paraná apresenta 33,21\% 
das matrículas, Santa Catarina, 54,18\% e Rio Grande do Sul, 48,32\%. Ou seja, dos três estados amostrados, é em Santa Catarina que o processo de implantação do EF9A demonstra estar mais acelerado.

Nos estados do Paraná e Santa Catarina, a rede federal de ensino consolidou a implantação em 2009, visto que em 2010 já não mais ocorreram matrículas no EF8A. O mesmo não acontece em relação às demais redes. Na rede estadual, quase não há movimentação no estado do Paraná (0,14\%), 34,95\% em Santa Catarina e 35,19\% no Rio Grande do Sul. Na rede municipal, há movimentação intensa nos três estados com 63,26\% no Paraná, 68,23\% em Santa Catarina e 61,51\% no Rio Grande do Sul.

Constata-se, portanto, que nas redes municipais, nas quais o contingente de matrículas é maior nos anos/séries iniciais, a transição foi mais intensa, sinalizando para uma sistemática de implantação na modalidade gradativa e não simultânea. Na rede privada, o movimento de transição é bastante equilibrado nos estados no Paraná e Rio Grande do Sul, movimentando em torno de $42 \%$ das matrículas e, mais intenso, no de Santa Catarina porquanto a rede transferiu $73,06 \%$ das matrículas para o EF9A até 2010.

$O$ quadro retratado revela que a implantação do EF9A não foi suficiente para estancar a redução no número de alunos matriculados no Ensino Fundamental, ainda que isso não signifique que mais crianças estejam fora das escolas. A redução da natalidade, e por consequência, no número de crianças em idade escolar, provavelmente é o fato de maior impacto nessa redução.

No que se refere à permanência e avanço dos estudantes no Ensino Fundamental, a Região Sul se destaca pelo baixo percentual de evasão das crianças do Ensino Fundamental. Enquanto no período compreendido entre 2007 a 2010 a média nacional ficou em 4\%, na Região Sul esse percentual ficou em 1,65\%, conforme demonstrado no Gráfico 4. 


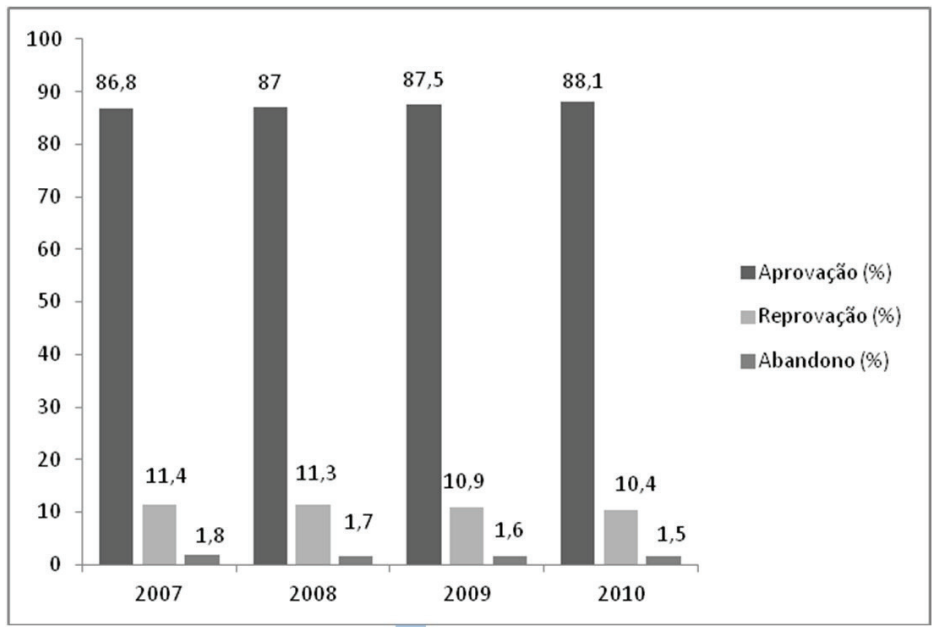

GRÁFICO 4 - Taxas de aprovação, reprovação e abandono no Ensino Fundamental, na Região Sul

Fonte: IBGE (2010, 2011).

Conquanto logre bons índices no tocante à permanência das crianças no Ensino Fundamental, o mesmo não ocorre com as taxas de reprovação. Como vimos, apesar de constante declínio nessas taxas ao longo do período inventariado, o percentual de reprovação na Região Sul é muito próximo da média nacional, tendo, no ano de 2010, ficado acima dela. Pelos dados retratados, um dos maiores desafios da Região Sul está justamente nas condições de aprovação dos alunos no Ensino Fundamental.

Considerando que, para um bom Ideb, escolas e redes precisam manter equilíbrio entre notas da Prova Brasil e taxas de aprovação, sendo ideal para esta um percentual em torno dos $97 \%$, vemos um desafio importante a ser enfrentado pelos estados do Sul nesse aspecto. Não obstante, como sabemos, boas taxas de aprovação não constituem, por si só, referencial de qualidade. No indicador adotado pelas atuais políticas públicas, as notas da Prova Brasil representam os outros 50\% dessa equação composta por duas variáveis (aprovação + Prova Brasil). Assim, um equilíbrio entre boas taxas de aprovação (na casa dos 97\%) 
e bom desempenho dos estudantes na Prova Brasil, representariam, via de rega, um bom Ideb.

$\mathrm{Na}$ TAB. 16, estão retratados os resultados alcançados pelos municípios dos três estados sulinos no Ideb de 2011.

\section{TABELA 16}

Resultados Ideb 2011, no Brasil e estados da Região Sul

\begin{tabular}{l|c|c|c|c|c|c}
\cline { 2 - 7 } & \multicolumn{3}{c|}{ ANOS INICIAIS } & \multicolumn{3}{c}{ ANOS FINAIS } \\
\hline Rede & Pública & Privada & Total & Pública & Privada & Total \\
\hline Brasil & 4,7 & 6,5 & 5,0 & 4,1 & 6,0 & 4,1 \\
Região Sul & 5,4 & 6,9 & 5,5 & 4,2 & 6,2 & 4,8 \\
Paraná & 5,4 & 7,0 & 5,6 & 4,1 & 6,3 & 5,6 \\
Santa Catarina & 5,7 & 7,1 & 5,8 & 4,7 & 6,4 & 4,9 \\
Rio Grande do Sul & 5,1 & 6,7 & 5,1 & 3,9 & 6,1 & 4,1 \\
\hline
\end{tabular}

Fonte: MEC/Inep (BRASIL, 2011)

O Ideb tem como meta a nota 6,0 (seis) a ser atingida no ano de 2021, segundo expectativas do MEC/Inep (BRASIL, 2011). Para assegurar que esse resultado seja atingido no prazo estipulado, foram estabelecidas metas intermediárias por escola, por município e para anos inicias e anos finais do Ensino Fundamental. No Ideb de 2011 (BRASIL, 2011), a média nacional ficou acima da meta prevista para o biênio (4,6 para os anos iniciais e 3,9 para os anos finais). A superação das metas também ocorreu em relação aos estados sulinos. As médias da Região ficaram acima da média nacional. Dentre os três estados, Santa Catarina se destaca com o melhor Ideb tanto nos anos iniciais como nos anos finais.

Em relação à passagem do Ensino Fundamental para o Médio, observando apenas o ano de 2010, a Região Sul registrou 1.998.041 matrículas nos anos finais e 1.050.967 no Ensino Médio regular. A taxa de abandono no Ensino Médio ficou em 10,3\% e a de reprovação em 12,5\%. Ou seja, menos de $60 \%$ dos estudantes que estão cursando os anos finais do Ensino Fundamental chegarão ao final da Educação Básica.

Dentre os três estados sulinos, o Rio Grande do Sul é o que deteve o maior percentual de reprovação no Ensino Médio (19,5\%); Santa Catarina 
obteve um percentual de 10,4\% e o Paraná 11,7\%. O Rio Grande do Sul é também o estado que obteve a maior taxa de abandono (11\%); Santa Catarina ficou em 7,1\% e o Paraná 6,7\%.

Nos dados expostos, encontramos outra evidência do argumento que vimos construindo ao longo do texto. Os estados estão demonstrando capacidade limitada de agir e implementar ações que respondam adequada e organicamente ao problema da permanência com qualidade no Ensino Fundamental. O movimento é sazonal e insuficiente para promover mudanças estruturais no processo educativo. À medida que os estudantes avançam nas etapas de escolarização diminuem as chances de êxito escolar.

\section{Considerações finais}

Os dados levantados sobre os três estados da Região Sul, no período de 2005 a 2010, possibilitam algumas sínteses:

1. o movimento de transição das matrículas dos EF8A para o EF9A é constante no período amostrado, porém a concentração mais significativa ocorre entre os anos de 2006 a 2008, o que pode indicar justamente o período em que as redes iniciaram a implantação da Lei n. 11.274/2006; 2. as redes municipais de ensino são as responsáveis pelo maior contingente de matrículas na transição de uma modalidade para outra. Essa concentração responde a dois fatores: (i) a opção por um processo de implantação do EF9A gradativo, iniciando pelos anos/séries iniciais do Ensino Fundamental e (ii) por ser justamente na rede municipal, em virtude do processo de municipalização ocorrido em âmbito nacional, onde está concentrada a maior porção das matrículas dos anos iniciais; 3. apesar de ter havido incremento de alunos com a implantação do EF9A, há um movimento de redução das matrículas nos três estados sulinos, confirmando uma tendência observada em âmbito nacional de redução no número de alunos que ingressam no Ensino Fundamental. De acordo com o INEP, as causas na retração das matrículas estão ligadas à contínua queda na taxa de natalidade e à diminuição nos índices de repetência, especialmente nos anos iniciais. Ocorre, no entanto, fenômeno 
inverso na rede particular, que logrou, entre 2005 e 2010, um aumento de 2.337.051 no total de matrículas no Ensino Fundamental, fenômeno esse observado nacionalmente.

No caso específico da Região Sul, observa-se evasão das matrículas da rede pública para a rede particular, com destaque para o Paraná (21\%) e Santa Catarina (10\%). Essa redução, ratificada nos dados nacionais, nos leva a desconfiar dos objetivos anunciados como principais para a implantação do EF9A, ou seja, de melhoria da qualidade educacional no Ensino Fundamental. A contenção da acentuada redução de matrículas não seria um dos objetivos, talvez o principal, da ampliação da escolaridade obrigatória? Essa ampliação não estaria mobilizada mais pelas questões quantitativas do cenário educacional nacional do que pelas qualitativas, anunciadas no discurso oficial que justifica a necessidade de ampliação da escolarização obrigatória para nove anos?

Os dados corroboram a evidência, apontada em outros estudos (OLIVEIRA; ARAUJO, 2005; FERNANDES, 2010, entre outros) de que, apesar dos esforços positivos para a universalização da educação mínima obrigatória e do notável aumento nas condições de seu acesso, o Ensino Fundamental continua a produzir desigualdades. Uma das razões dessa constatação é justamente o quadro de considerável expansão das matrículas na rede privada de ensino.

Está havendo um movimento migratório das matrículas da rede pública para a rede privada aos moldes do que ocorreu na década de 80, quando fora decretada a falência da escola pública. Ainda que seja devido comemorar a expansão nas condições de acesso ao Ensino Fundamental, a permanência com qualidade na educação pública constitui um dos desafios, se não o maior, das políticas em curso. Conforme afirmam Franco, Alves e Bonamino (2007) a "universalização da conclusão do ensino fundamental ainda é um desafio a ser completado".

As conquistas quantitativas em relação ao acesso e o processo de funil gradativo vivenciado pelos estudantes no avanço em direção ao Ensino Médio demonstram que as iniciativas empreendidas com a ampliação da escolaridade mínima ainda estão longe de alcançar a tão almejada qualidade na Educação Básica, ao menos do ponto de vista das condições 
de êxito escolar.

O desafio da permanência compreende esforços políticos relativos ao ensino e à aprendizagem. Esses dois âmbitos, indissociáveis da prática educativa, exigem atenção acerca das condições inerentes à profissionalidade docente, aos insumos e, especialmente, ao currículo, questão ainda pendente nessa reforma. 


\section{Referências}

BRASIL. Lei de Diretrizes e Bases da Educação Nacional n. 9.394/1996, de 20 de dezembro de 1996. Brasília: MEC. Disponível em: <http:/ / www.mec.gov.br/legis/pdf/LDB.pdf>. Acesso em: 05 mai. 2012.

BRASIL. INEP. Sinopse Estatística da Educação Básica - 2000. 2000. Disponível em: <http:/ / portal.inep.gov.br/basica-censo-escolarsinopse-sinopse>. Acesso em: 20 nov. 2012.

BRASIL. INEP. Sinopse Estatística da Educação Básica - 2001. 2001. Disponível em: <http:/ / portal.inep.gov.br/basica-censo-escolarsinopse-sinopse>. Acesso em: 20 nov. 2012.

BRASIL. INEP. Sinopse Estatística da Educação Básica - 2002. 2002. Disponível em: <http:/ / portal.inep.gov.br/basica-censo-escolarsinopse-sinopse>. Acesso em: 20 nov. 2012.

BRASIL. INEP. Sinopse Estatística da Educação Básica - 2003. 2003. Disponível em: <http:/ / portal.inep.gov.br/basica-censo-escolarsinopse-sinopse>. Acesso em: 20 nov. 2012.

BRASIL. Ministério da Educação. Secretaria de Educação Básica. Ampliação do ensino fundamental para nove anos. Brasília, DF: 2004a. Relatório.

BRASIL. INEP. Sinopse Estatística da Educação Básica - 2004. 2004b. Disponível em: <http:/ / portal.inep.gov.br/basica-censo-escolarsinopse-sinopse>. Acesso em: 20 nov. 2012.

BRASIL. Lei n. 11.114, de 6 de novembro de 2005. Altera os artigos 6, 30, 32 e 87 da Lei n.9.394/96, de 20 de dezembro de 1996, com o objetivo de tornar obrigatório o início do ensino fundamental aos seis anos de idade. Diário Oficial da União, Brasília, 2005a. 
BRASIL. INEP. Sinopse Estatística da Educação Básica - 2005. 2005b. Disponível em: <http:/ / portal.inep.gov.br/ basica-censo-escolarsinopse-sinopse>. Acesso em: 20 nov. 2012.

BRASIL. Lei n. 11.274, de 6 de fevereiro de 2006. Altera a redação dos artigos 29, 30, 32 e 87 da Lei 9.394, de dezembro de 1996, dispondo sobre a duração de 9 (nove) anos para o ensino fundamental, com matrícula obrigatória a partir dos 6 (seis) anos de idade. Diário Oficial da União, Brasília, 7 fev. 2006a.

BRASIL. INEP. Sinopse Estatística da Educação Básica - 2006. 2006b. Disponível em: <http:/ / portal.inep.gov.br/basica-censo-escolarsinopse-sinopse>. Acesso em: 20 nov. 2012.

BRASIL. INEP. Sinopse Estatística da Educação Básica - 2007. 2007. Disponível em: <http:/ / portal.inep.gov.br/basica-censo-escolarsinopse-sinopse>. Acesso em: 20 nov. 2012.

BRASIL. INEP. Sinopse Estatística da Educação Básica - 2008. 2008. Disponível em: <http:/ / portal.inep.gov.br/basica-censo-escolarsinopse-sinopse>. Acesso em: 20 nov. 2012.

BRASIL. Emenda Constitucional n. 59, de 11 de novembro de 2009. Diário Oficial da União: Brasília, 12 nov. 2009a.

BRASIL. INEP. Sinopse Estatística da Educação Básica - 2009. 2009b. Disponível em: <http:/ / portal.inep.gov.br/basica-censo-escolarsinopse-sinopse>. Acesso em: 20 nov. 2012.

BRASIL. Presidência da República. Sinopse das Ações do Ministério da Educação. Nov. 2010a. Disponível em: <http:/ / gestao2010.mec.gov. br/download/sinopse_acoes_mec.pdf> Acesso em: 05 out. 2012. BRASIL. INEP. Sinopse Estatística da Educação Básica - 2010. 2010b. Disponível em: <http:/ / portal.inep.gov.br/basica-censo-escolar- 
sinopse-sinopse>. Acesso em: 20 nov. 2012.

BRASIL. INEP. Censo Escolar da Educação Básica - Educacenso 2010. 2010c. Disponível em: <http:/ / portal.inep.gov.br/basica-censoescolar-sinopse-sinopse>. Acesso em: 20 nov. 2012.

BRASIL. INEP. Índice de Desenvolvimento da Educação Básica resultados e metas 2011. Disponível em: <http://ideb.inep.gov.br/>. Acesso em: 20 nov. 2012.

DURLI, Zenilde; SCHNEIDER, Marilda Pasqual. O ensino fundamental de nove anos: desafios à formação de professores. Revista Retratos da Escola. Brasília, v. 4, n. 7, p. 329-340, jul./dez. 2010.

FARENZENA, Nalú. A Emenda da obrigatoriedade: mudanças e permanências. Revista Retratos da Escola, Brasília, v. 4, n. 7, p. 197-209, jul./dez. 2010.

FERNANDES, Francisco das Chagas. Educação básica obrigatória e gratuita: avanços e desafios. Revista Retratos da Escola, Brasília, v. 4, n. 7, p. 183-195, jul./dez. 2010.

FRANCO, Creso; ALVES, Fátima; BONAMINO, Alicia. Qualidade do ensino fundamental: políticas, suas possibilidades, seus limites. Educ. Soc., Campinas, v. 28, n. 100, p. 989-1014, out. 2007.

GORNI, Doralice Aparecida Paranzini. Ensino Fundamental de 9 anos: estamos preparados para implantá-lo? Ensaio, Rio de Janeiro, v. 15, n. 54, p. 67-80, jan./mar. 2007.

IBGE. Séries Estatísticas \& Históricas. 2009. Disponível em: <http:/ / seriesestatisticas.ibge.gov.br $/$ listatema.aspx?op $=0 \&$ no=4> Acesso em: 05 out. 2012. 
IBGE. Séries Estatísticas \& Históricas. 2010. Disponível em: <http:/ / seriesestatisticas.ibge.gov.br/listatema.aspx?op $=0 \&$ no $=4>$ Acesso em: 05 out. 2012.

IBGE. Séries Estatísticas \& Históricas. 2011. Disponível em: <http:/ / seriesestatisticas.ibge.gov.br $/$ listatema.aspx?op=0\&no=4> Acesso em: 05 out. 2012.

OLIVEIRA, Romualdo Portela de; ARAÚJO, Gilda Cardoso de. Qualidade do ensino: uma nova dimensão da luta pelo direito à educação. Revista Brasileira de Educação, Rio de Janeiro, n. 28, p. 5-23, jan./fev./mar./abr. 2005.

PINTO, Jóse Marcelino de; ALVES, Thiago. Ampliação da obrigatoriedade na educação básica: como garantir o direito sem comprometer a qualidade? Revista Retratos da Escola, Brasília, v. 4, n. 7, p. 173-406, jul./dez. 2010.

SAVELI, Esméria de Lourdes. Ensino Fundamental de nove anos: desafios pela sua efetiva implantação. In: SEMINÁRIO DE PESQUISA EM EDUCAÇÃO DA REGIÃO SUL, 7., 2008. Anais... Itajaí, 2008.

SCHNEIDER, Marilda Pasqual; DURLI, Zenilde. Ensino Fundamental de nove anos: aspectos legais e didático-pedagógicos. Roteiro, Joaçaba, v. 34, n. 2, p. 189-214, jul./ dez. 2009a.

SCHNEIDER, Marilda Pasqual; DURLI, Zenilde. O ensino fundamental é de nove anos: e agora? In: CONGRESSO NACIONAL DE EDUCAÇÃO, 9., 2009b. Anais... Paraná, 2009b. Disponível em: <http:/ / www.nre.seed.pr.gov.br/cianorte/arquivos/File/PEDAGOGAS/ NOVE_ANOS/NOVEANOSEAGORA.pdf>. Acesso em: 20 jun. 2012.

Recebido: $12 / 11 / 2012$ Aprovado: 03/02/2013 